\title{
Severe Anemia, Hemoptysis, and Melena with Rapidly Crescentic Glomerulonephritis
}

DHARMENDRA BHADAURIA, MD, DM, Assistant Professor; AMIT MAHAPATRA, MD, DM, Senior Resident; AJAY SINGH, MD, DM, Senior Resident; ANUPMA KAUL, MD, DM, Associate Professor; NARAYAN PRASAD, MD, DM, Additional Professor; RAJ KUMAR SHARMA, MD, DM, Professor; HIRA LAL, MD, DM, Professor; SAMEER MOHINDRA, MD, DM, Associate Professor of Gastroenterology, Department of Nephrology and Renal Transplantation, Sanjay Gandhi Post Graduate Institute of Medical Sciences, Lucknow, India. Address correspondence to Prof. Bhadauria; E-mail: drdharm1@ rediffmail.com. J Rheumatol 2014;41:1893-4; doi:10.3899/jrheum.140217

Our case represents the first description of Klippel-Trenaunay-Weber syndrome along with rapidly progressive glomerulonephritis (RPGN). A 58-year-old man presented with edema and oliguria for 25 days associated with hemoptysis and melena. He had profound anemia (hemoglobin $7.1 \mathrm{~g} / \mathrm{dl}$ ), azotemia (serum creatinine 6.2 $\mathrm{mg} / \mathrm{dl}$ ) with nephrotic range proteinuria (24-hour urinary protein $4.2 \mathrm{~g}$ ), active urinary sediment (30-40 red blood cells/high power field by urine microscopy), and stool positive for blood. Suspicion of systemic vasculitis was determined because of RPGN along with gastrointestinal (GI) and pulmonary manifestations. He had had spontaneous fractures of right humerus in 1996 and 2009. His right arm and forearm were deformed and enlarged, with multiple

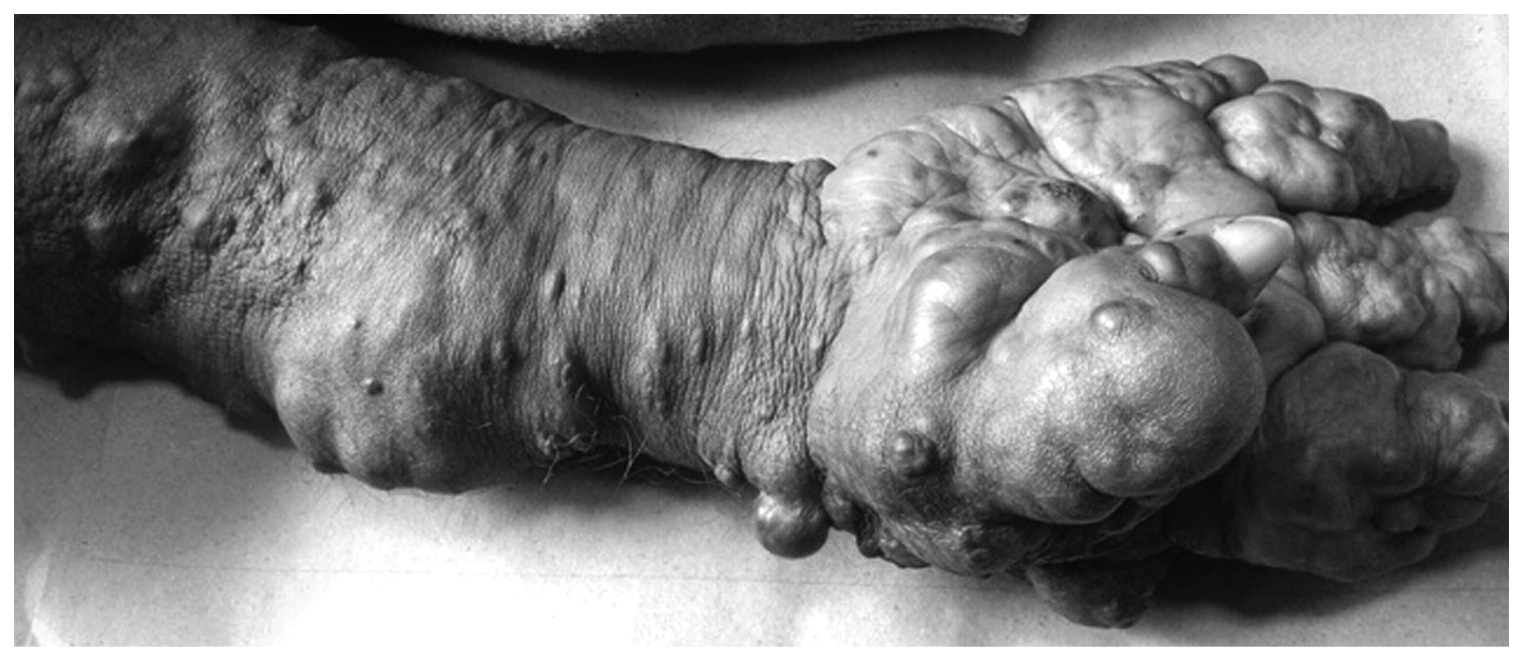

A

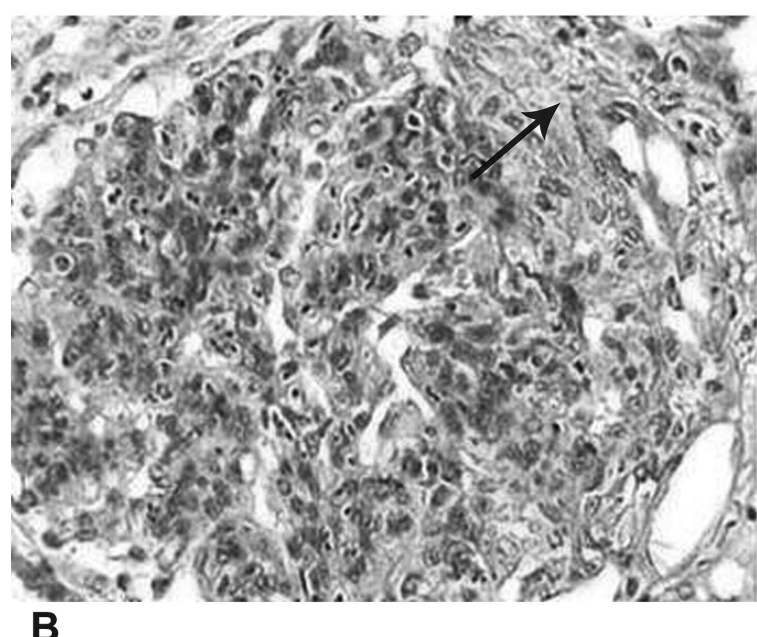

B

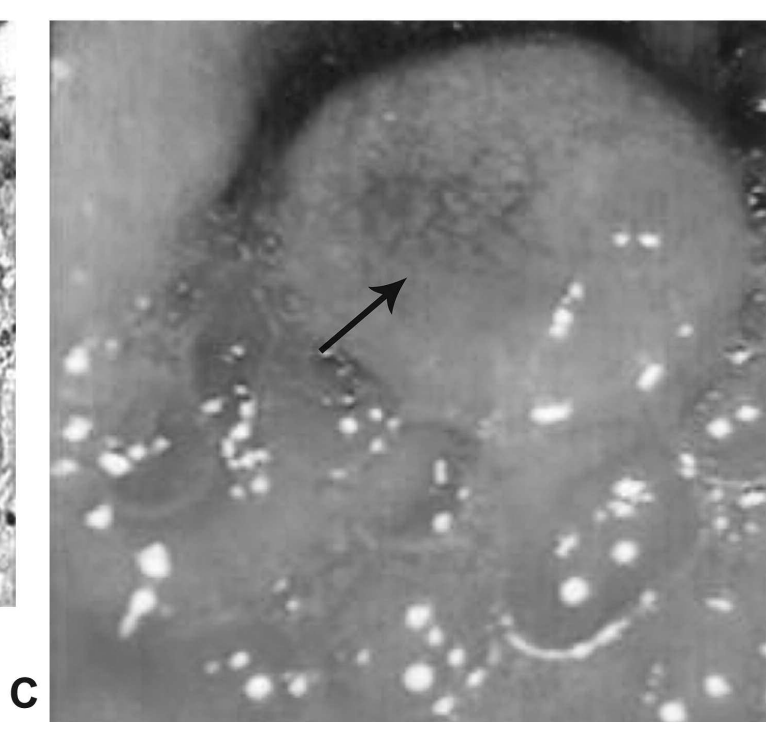

Figure 1. A. The upper limb, arterio-venous malformation in the form of nodules with gigantism. B. Light micrograph of glomerulus; arrow indicates endocapillary proliferation with crescent formation (PAS stain). C. Upper gastrointestinal endoscopy; arrow indicates angiodysplasia of D1 and $\mathrm{D} 2$ region. 
varicose veins (Figure 1A). Renal histopathology showed endocapillary proliferation with focal necrotizing crescents (Figure 1B) present in 12/21 glomeruli. Antinuclear cytoplasmic antibody was negative, with low $\mathrm{C} 3$. He was treated with parenteral methylprednisolone followed by oral prednisolone $(1 \mathrm{mg} / \mathrm{kg} /$ day $)$ and oral cyclophosphamide (1.5 $\mathrm{mg} / \mathrm{kg}$ body weight). His serum creatinine diminished to 1.2 $\mathrm{mg} / \mathrm{dl}$. He received 10 units of packed red-cell transfusions for profound anemia. Upper GI endoscopy showed submucosal growth at the D1/D2 junction of the duodenum (Figure 1C). This case illustrates Klippel-Trenaunay-Weber syndrome due to abnormalities of blood vessels and lymphatic system along with RPGN, mimicking systemic vasculitis. Abnormalities were venous and lymphatic malformation and soft-tissue hypertrophy of the affected limb leading to local gigantism (Figure 1A). Hemoptysis and GI hemorrhage were due to vascular malformation of lungs and intestine, respectively, whereas RPGN might have been due to post-infectious glomerulonephritis after cutaneous infection of limb lesions (crescentic glomerulonephritis and low complement). This is the first case description of Klippel-Trenaunay-Weber syndrome concurrently with RPGN. 